\title{
LAS METÁFORAS DE UN DÍA EN LOS MEDIOS DE COMUNICACIÓN ESPAÑOLES
}

\author{
LEONOR RUIZ GURILLO \\ (Universidad de Alicante) \\ Unidad Singular de Investigación en Lingüística Cognitiva
}

\begin{abstract}
This paper takes up the Idealized Cognitive Models (ICM, Lakoff, 1987) used in mass media about the breaking of ETA's truce: PEACE IS A WAY, TERRORISM IS $A$ ILLNES, ctc. The article starts by describing the metaphoric and metonimic aspects of ${ }_{i C M}{ }^{\prime} s$. The rest of the article reviews some of the aspects ot the comprehension of melaphors: cognitive acquisition, implicatures and inferences.
\end{abstract}

\section{Introducción}

Las metáforas constituyen una parte importante del lenguaje no literal. Las lenguas naturales se fundamentan tanto en unidades y expresiones de significado literal como en aquellas que presentan algún tipo de desviación. La desviación parece algo consustancial a la esencia de las lenguas, que están impregnadas de estos mecanismos. Los actos de habla indirectos, la ironía, las unidades frascológicas o las metáforas son ejemplos de este lenguaje no literal o traslaticio (Belinchón, 1999) y requieren de procedimientos cognitivos especiales de interpretación que los seres humanos desarrollamos de forma natural en el proceso de adquisición del lenguaje, empleando para ellos diversas fases de metarrepresentación y de suspensión de las relaciones entre referencia y verdad (Rivière, 1999).

De estos mecanismos no literales destaca la metáfora de la que se va a ocupar este artículo. Para su análisis se empleará un corpus de prensa escrita y de radio referente a una única noticia, la ruptura de la tregua por parte de la banda terrorista 
ETA, que será analizado empleando el basamento teórico que ofrece la lingüística cognitiva, en especial lo que se refiere al concepto de modelo cognitivo idealizado. Se estudiarán los modelos que se encuentran implicados en la generación de las noticias sobre este tema y, tras el análisis, se perfilarán ciertos mecanismos que intervienen en la generación y en la comprensión del lenguaje no literal y, en concreto, de la metáfora, pues nos ofrecen una explicación de los recursos encontrados.

\section{Los modelos cognitivos idealizados}

Frente a las posturas más tradicionales de la metáfora, la visión cognitiva la considera uno de los fundamentos de los procesos mentales. De hecho, influye sobre la gramaticalización ${ }^{1}$ o los modelos cognitivos idealizados y sustenta buena parte del lenguaje no literal. Los seres humanos nos servimos de nuestro conocimiento sobre el mundo y sobre nosotros mismos para expresar conceptos e ideas. Ello supone que las ideas sobre el pensamiento, la ciencia o los sentimientos se basarán a menudo en nociones corporales o, dicho de otro modo, en esquemas encarnados (Johnson, 1992). La corporeización del lenguaje es una de las hipótesis más fuertes del cognitivismo. Supone que los usos metafóricos, metonímicos o de otro tipo que encontramos en las lenguas no funcionan aisladamente; al contrario, se deben a procesos psicolingüísticos. Por lo tanto, es probable que estos encuentren reflejo en las diversas lenguas del mundo.

La conceptualización del mundo por medio de nociones corporales o de la experiencia encuentra su molde teórico en el modelo cognitivo idealizado (Lakoff, 1987)2. Este constituye una compleja base que se apoya en cuatro principios de esquematización: una estructura proposicional, una estructura de imágenes esquemáticas, las proyecciones metafóricas y las proyecciones metonímicas. Empleando la delinición de Ungerer y Schmid (1996:5, apud Cuenca y Hilferty, 1999) un modelo cognitivo es una «visión cognitiva, y básicamente psicológica, del conocimiento almacenado sobre un cierto campo». Estos se reparten en modelos culturales diferentes, que dependen de los grupos o subgrupos sociales. De este modo, existen modelos cognitivos coincidentes entre las diferentes culturas, pero también modelos culturales divergentes unos de otros.

\footnotetext{
'La teoría de la gramaticalización facilita un tratamiento integrador de los cambios evolutivos del lenguaje a partir de su actuación en el discurso. En palabras de Traugott y Heine (1991:1), «gramaticalization is the linguistic process, both through time and synchronically, of organization of categories and of coding》.

2 El modelo cognitivo idealizado de Lakoff coincide con el dominio cognitivo de Langacker (1987,1991), el marco de Fillmore (1985) el espacio mental de Fauconnier (1984) y se relacionan con los conceptos de guión o o de marco de la psicología y la inteligencia artificial.
} 
Sobre los modelos cognitivos se organizan las estructuras categoriales y los diversos efectos prototípicos. Estos patrones o modelos permiten procesar información abstracta a partir de conceptos más cercanos, por ejemplo, a partir de nociones físicas. De entre los numerosos ejemplos de Lakoff y Johnson (1991) destacamos las metáforas ontológicas referidas al amor, como EL AMOR ES UN PACIENTE, EL AMOR ES UNA LOCURA O EL AMOR ES UNA GUERRA, que dan como resultado expresiones como «el matromonio está muerto, no se le puede hacer revivir», «ella me hechizó» o «luchó por él, pero su amante venció». De este modo, las meláloras se sustentan en nuestra experiencia física, pero, al mismo tiempo, influyen en nuestra experiencia y en nuestras acciones.

La metáfora, la metonimia o las imágenes esquemáticas permiten dar coherencia a la estructura proposicional que desarrolla el modelo cognitivo. Aseguran una conceptualización más sencilla y comprensible. Estos modelos se esparcen por las lenguas de maneras muy diferentes. A veces las expresiones que cncontramos cstán tan lexicalizadas que ya no detectamos el procedimiento metafórico que le dio origen. En otras ocasiones son estructuras plenamente vigentes en la lengua o constituyen creaciones personales. Ello supone que existen diversos grados de consolidación de una metáfora, por lo que podríamos diferenciar, con Chamizo (1997), tres tipos distintos en un corte sincrónico: lexicalizadas, scmilexicalizadas y creativas.

Las expresiones metafóricas interactúan en la lengua con las de carácter literal o con aquellas en las que ya no se percibe su metaforización. Así pues, se separarían cuatro lipos de expresiones que recogen los usos léxicos y su posible combinación semántica (Bickerton, 1969, apud, Martínez-Dueñas, 1993):

a). Expresiones literales (barra de hierro; gato negro).

b). Asignaciones permanentes (disciplina de hierro; rata asquerosa).

c). Expresiones provisionales (pensamientos rojos; palabra de acero).

d). Expresión sin significado (la duplicidad bebe dilación).

Solo las expresiones de (c) son las propiamente metafóricas. Las de (b) pertenecen a la fraseología y solo esporádicamente las de (d) vienen a convertirse en metáloras.

En cste trabajo nos releriremos en especial a las del grupo (c), lo que no obsta para hacer alguna reflexión en torno a las expresiones que pertenecen a los grupos (b) y (d). Para llevar a cabo nuestro análisis, observaremos el modelo cognitivo o la metálora básica que la sustenta, así como la realización sintáctica que presenta la cxpresión metafórica concreta (nominal, predicativa u oracional; Levinson, 1989:138-152). 
El corpus se ha extraído de los medios de comunicación social ${ }^{3}$ y se refiere a un único tema: la ruptura de la tregua por parte de la banda terrorista ETA, que se anunció el domingo 28 de noviembre de 1999. Tras 14 meses sin atentados, este hecho produjo entre la opinión pública un gran estupor y durante unos días esta noticia atrajo todas las atenciones informativas. Se repetía con frecuencia, empleando una metáfora, que ETA había secuestrado la actualidad. Tras una cala en la prensa escrita y en la radio de los días posteriores, en especial del día siguiente del anuncio de la ruptura, lunes 29 de noviembre, se ha observado el empleo de diversas metáforas, metonimias o imágenes esquemáticas que se apoyan en un modelo cognitivo idealizado. Estas afloran primordialmente en los artículos periodísticos de opinión y en las tertulias radiofónicas, si bien también se encuentran en otros textos más neutros, como el comunicado del presidente del gobierno.

Las primcras reacciones ante la noticia contenían numerosas metáforas lexicalizadas, esto es, que han dado como resultado una unidad fraseológica o cstructura lijada. Se trata de manifestaciones orales con cierto grado de espontancidad. En estos casos recurrir a una metáfora ya construida y establecida por el uso suele dar buenos resultados en el proceso de comunicación, pues resume en muy pocas palabras todo el conocimiento que encierra esa expresión. Así ocurre con agujero negro (1), como un jarro de agua fría (2) o poner los pelos de punta (3):

\section{(1) «Esto es un agujero negro» (RNE1).}

En (1) encontramos un uso trasladado del compuesto sintagmático agujero negro. Acudiendo a las similitudes que existen entre este fenómeno astronómico y la situación creada por ETA, se lleva a cabo un trasvase del dominio físico al dominio de las ideas. Ello permite aplicar ciertas propiedades de la manifestación lísica a la noción conceptual, en especial su oscuridad, el hecho de ser algo prácticamente desconocido y la idea de que se trata de un abismo. De este modo se identilica la ruptura de la tregua con un agujero negro, esto es, se conceptualiza como algo oscuro, desconocido y abismal.

(2) «Nos ha caído la noticia como un jarro de agua fría» (RNEI).

Este recurso se emplea también en (2), donde el proceso de lanzar un jarro de agua fría sobre alguien actúa como pivote del nuevo sentido metafórico,

\footnotetext{
${ }^{3}$ Los diarios cxaminados son El País, El Mundo, Diario 16, ABC y La Verdad. El corpus extraído do radio pertencee a las entisiones de Radio Nacional de España (RNEI), Cadena SER y Canal 9 Radio.
} 
«sorprenderse». El hecho físico se proyecta sobre el efecto que ha tenido la noticia, de modo que se lleva a cabo la identificación.

(3) «Es algo que realmentc a las víctimas del terrorismo nos pone los pelos de punta» (Canal 9 Radio).

E] origen de poner los pelos de punta se encuentra a una imagen esquemática. Las imágenes esquemáticas, cuyo concepto se debe a Mark Johnson, son, según palabras de Cuenca y Hilferty (1999:106) «una subclase de imágenes conceptuales (...) que surge de experiencias perceptuales y motoras recurrentes en el curso del desarrollo. (...) Las imágenes esquemáticas, pues, son el producto de nuestra habilidad de csquematizar y reconocer similitudes entre objetos y situaciones». En este caso, la reacción física de carácter ancestral, que nos recuerda que reaccionamos de igual modo que otros animales ante el frío y otros hechos externos, sustenta, gracias a un proceso metafórico, la imagen generadora del nuevo sentido de la expresión, «exasperar(se), enervar(se)". La unidad fraseológica fija esa imagen y permite aplicarla a un concepto. Su realización discursiva supone que la nueva situación exaspera a las víctimas del terrorismo.

Estos tres fragmentos dan una idea de las valoraciones llevadas a cabo de forma espontánca: la ruptura de la tregua produce sentimientos muy diversos como la sorpresa o la cxasperación, en especial porque la nueva situación que se vislumbra es totalmente desconocida.

El análisis más meditado permite observar diversos modelos cognitivos idealizados que vertebran la construcción de metáforas. Destacan los referentes a la paz, estructurados a partir de las metáforas básicas LA PAZ ES UN CAMINO, LA PAZ ES UNA PARTIDA DE CARTAS O LA PAZ ES UNA ACTIVIDAD EMPRESARIAL. De esta mancra, cl modelo LA PAZ ES UN CAMINO es el más consolidado. Al parecer, se asocia a la frase de Gandhi que, gracias a su difusión, facilita la construcción de estructuras en diversas lenguas y actúa como metáfora básica o patrón del modelo cognitivo. El diario El Mundo encabezaba su publicación del lunes 29 de novicmbre con la cita de este pacifista: «No hay camino para la paz, la paz es cl camino".

A partir de esta conceptualización de la paz como camino se construyen otros cnunciados que en nuestro corpus se hallan dispersos en diversos tipos de texto. Aunque en especial abundan en los artículos de opinión, también se encuentran en otros discursos de carácter más objetivo. El comunicado de ETA registra alguna metáfora basada en él:

(4) «AI lin y al cabo, se manifestaba en los que caminaban en el proceso la lalta de voluntad para llevar a la masa crítica que hay en Euskal Herria a una situación domocrática y para activar del todo las fuerzas» (publicado en El País). 
El propio presidente del gobierno, J. $\mathrm{M}^{\mathrm{a}}$ Aznar, terminaba su comunicado diciendo:

(5) «Tengo la seguridad de que triunfará la voluntad de paz que todos los españoles compartimos y que entre todos haremos realidad ese camino de esperanza» (publicado en Diario 16).

Los modos de construcción de expresiones metafóricas sobre este modelo cognitivo son diversos. En ciertos contextos, la proyección metafórica es evidente, pues junto a paz se encuentran los conceptos de meta, camino, vía, horizonte, ruta, integrados en enunciados como «allanar los caminos de la paz», «avanzar por el camino de la paz», «tomar el único camino posible», «marcar las rutas», etc.:

(6) «Es mucho lo que Euskal Herria ha avanzado en estos años en el camino de la libertad» (Comunicado de ETA; El País).

(7) «La paz es una meta por sí misma y sin concesiones» (ABC).

(8) «Sólo la decisión de los demócratas podrá allanar los caminos de la paz» (Diario 16).

(9) «Nunca hay argumentos que justifiquen estos crímenes y menos aún cuando el Gobierno nunca ha cerrado las puertas al diálogo, única vía de avanzar por el difícil camino del proceso de paz» (Diario 16).

(10) «El gobierno ha tomado el único camino posible» (La Verdad).

(11) «Todos los intervinientes en él han estado más pendientes de sus respectivos electorados y de los correspondientes comunicados periodísticos que de avanzar prudentemente y sin estridencias por el camino de la paz» (Diario 16).

(12) «Era la mejor prueba de que los etarras habían orillado definitivamente la vía pacífica» $(A B C)$.

(I3) «Mientras tanto, el Gobierno, la oposición y la sociedad española pueden y deben permanecer unidos, dejando al margen a la esperanza, pero con una lucidez. que permita comprender que estos últimos meses han dejado la huella de una posibilidad de paz que pronto se convertirá, por la fuerza de la razón, en un horizonte de paz auténtica que vendrá de la mano del tesón del Estado de Derecho y del cjercicio de la libertad» (ABC).

(14) «Scría imprescindible que ETA reconsiderase su postura pues si, como ella misma reconoce, se ha avanzado en los últimos meses, es obvio que el propio proceso de Construcción Nacional por el que dice apostar sólo podrá conseguirse desde vías pacíficas según el camino marcado en los últimos tiempos» (Diario 16). (15) «Pues porque las rutas, por mucho que se niegue, las marcaba ETA» (Diario 16).

Otras veces se abunda en la idea que de, una vez cortado el camino de la paz, la salida está también cortada, es un túnel o es un abismo: 
(16) «Porque de lo que aquí se trata es de hacer entender a los terroristas que por la vía de los asesinatos su salida está cegada» (ABC).

(17) «[En cambio] caminan hacia el final de túnel en Irlanda» (Canal 9 Radio).

(18) «Sería la prueba de que esta línea política [la de Arnaldo Otegui, líder de Euskal Herritarok, presunto brazo político de ETA] se va al abismo [si hay un atentado]» (Cadena SER).

(19) «Es muy posible que el nacionalismo sociológico se deba alguna autoestima $\mathrm{c}$ impulsc una democratización interna en sus órganos políticos que no permita en un futuro que una cúpula irrresponsable le conduzca al borde del abismo» (ABC).

En consecuencia, la paz está «atascada» y hay que buscar salida:

(20) «Pero mientras no logre adueñarse de su propio destino y lo delegue en líderes que han demostrado no saber estar a la altura de las circunstancias, habrán de ser Éstos los que salgan del atolladero» $(\mathrm{ABC})$.

Como sc ha observado, la mayor parte de estructuras construidas sobre este modelo son metáforas semilexicalizadas o creativas, de acuerdo con Chamizo (1997). Tan solo estar al borde del abismo y salir del atolladero conforman cxpresiones con algún grado de fijación. La primera es una locución prepositiva, al borde de, que rellena de forma libre el complemento al que sirve de enlace. La segunda es una locución verbal construida conceptualmente empleando el hecho físico de quedarse atascado en un lodazal u otro sitio similar.

Muy pocas de estas expresiones tienen estructura nominal (entre las registradas, únicamente la cita de Ghandi); la mayor parte son predicativas (como allanar los caminos de la paz, avanzar por el camino de la paz, tomar el único camino posible, orillar definitivamente la vía pacífica o avanzar desde vias pacificas según el camino marcado).

Meses después de la ruptura de ETA, tras el atentado que costó la vida a José Luis López de Lacalle, el modelo cognitivo se repite, lo que corrobora su rentabilidad discursiva; esta vez, se argumenta que los demócratas han de volver al camino de la democracia:

(2I) «Qué nuevo asesinato, cuántos más horrores para que el nacionalismo vasco se encamine de nuevo por la senda democrática y aleje definitivamente toda sombra que complicidad con el fascismo?» (El País, 8-5-2000).

Sobre la paz lambién se proyectan otras metáforas que aluden a modelos menos consolidados y, en consecuencia, más creativos, como LA LUCHA ARMADA ES UN JUEGO DE CARTAS O LA LUCHA ARMADA ES UN NEGOCIO EMPRESARIAL. EI primero de ellos se proyecta en ejemplos como el siguiente: 
(22) «Al ver que no aparecía ninguna propuesta política ni estrategia concreta en ese momento en el que se jugaba el futuro de Euskal Herria, ETA subrayaba la necesidad de nuevas propuestas políticas y puso la suya sobre la mesa» (comunicado de ETA; El País).

Se obscrva en este caso cómo la negociación se plantea del mismo modo que una partida de cartas, en la que está en juego el futuro del País Vasco. Incluso se cmplea una imagen esquemática que alude a un gesto propio de este juego: poner sobre la mesa sus cartas o, en este contexto, su propuesta.

Sobre la misma proyección metáforica se construyen enunciados con expresiones como dar la baza (23), perder la partida (24) o ir de farol (25):

(23) «ETA no quiere dar la baza a Aznar de presentarse en marzo ante los electores con año y medio de paz en su activo como gobernante» (EI Mundo).

(24) «Ha perdido la partida. Sus bazas se han quedado al descubierto» (El Mundo).

(25) «Es lo que ha ocurrido $y$, por ello, hay que dar por sentado que ETA no va de farol y cumplirá sus amenazas» (El Mundo).

Especialmente interesantes resultan las estructuras quedarse al descubierto e ir de farol, pues son expresiones fijas propias del juego de cartas que, gracias al sentido ligurado que desarrollan, son aplicables a la situación generada por ETA.

A menudo, se hallan expresiones metafóricas creativas de carácter predicativo construidas sobre este modelo. Obsérvese cómo el verbo apostar adquierc un sentido trasladado:

(26) «Despreciando el pragmatismo y el análisis de otras organizaciones políticas como el IRA, que ha apostado abiertamente por la paz cediendo a muchas de sus pretensiones» (Diario 16).

(27) «Es pues el momento de reconsiderar esa ruptura. El Gobierno de Aznar tiene que seguir apostando por la vía del diálogo» (Diario 16).

(28) «Y le hizo creer a ETA que el PNV apostaba en serio por la construcción nacional de esa mítica Euskal Herria» (El Mundo).

(29) «Es obvio que el propio proceso de Construcción Nacional por el que dice apostar sólo podrá conseguirse desde vías pacíficas según el camino marcado en los últimos ticmpos» (Diario 16).

(30) « $\mathrm{Si}$ la decisión de los dirigentes nacionalistas consiste en alinearse con la democracia y el sistema constitucional y estatutario, dispondrán de la colaboración y ayuda de todos los estamentos sociales y políticos; si, por el contrario, su apuesta es por la csquizofrenia de una ambigüedad patológica, habrán de ser ellos y sólo ellos los que se enfrenten al terrorismo etarra que acabará por fagocitarlos» $(\mathrm{ABC})$. 
También tras uno de los asesinatos de ETA, el modelo cognitivo se vuelve a encontrar en los textos periodísticos:

(31) «Será difícil que EH se tome en serio sus exhortaciones a independizarse de ETA mientras Él mismo sea incapaz de tomar distancias respecto a su partido y éste mantenga su apuesta de alianza nacionalista entre demócratas y quienes no lo son» (El País, 8-5-2000).

(32) «Nadic puede ignorar que la temeraria apuesta nacionalista del pacto con ETA, prolongado en el de Lizarra, ha fracasado» (El País, 8-5-2000).

Otro de los modelos utilizados, LA LUCHA ARMADA ES UN NEGOCIO EMPRESARIAL, constituyc asimismo un esquema de construcción poco consolidado:

(33) «Arzalluz, que no ha podido reponer el dinero que se llevó de la caja -la lealtad del PNV hacia el Estatuto de Gernika- y ha dejado en quiebra la empresa de la paz, debe seguir el ejemplo de su antiguo compañero de partido» (El Mundo).

(34) «Los ctarras, que no saben qué hacer con sus pistolas y con las vidas de quienes les votan, deciden abrir de nuevo el negocio para ganar tiempo, destrozar vidas ajenas para hacer como que hacen política mientras se desenreda la herencia hipotecada de Sabin Etxea, la linca del nacionalismo vasco» (El Mundo).

(35) «Sucede que las funerarias son negocio. Y que dos firmas comerciales en quiebra se resisten a cerrar» (El Mundo).

En delcrminadas ocasiones se emplea el modelo EL PROCESO DE PAZ ES UN ÓRGANO VIVO. La argumentación que el comunicado de ETA construye sobre este modelo, le conduce a afirmar que, aunque la opción más valorada por ellos había madurado, con el paso del tiempo se ha podrido:

(36) «En una palabra, opinamos que la opción de cambiar el viejo marco jurídicopolítico que ha estado en vigor 20 largos años, que venía de la reforma de la dictadura, y de dar pasos consistentes en favor de un marco jurídico-político basado en la democracia de Euskal Herria, había madurado»

«Durante cl pasado verano ha sido notable la paralización y el olor a podredumbre del proceso»»

«Así las cosas, el proceso que comenzó el año pasado está sufriendo un claro bloqueo y se está pudriendo» (Comunicado de ETA; El País)

Abundando en un dominio origen similar, el terrorismo es observado por los demócratas como una enfermedad:

(37) «Prefieren la úlcera del terrorismo que genera anualmente menos muertos que los accidentes de tráfico de un fin de semana, a lo que denominan el cáncer político» (El Mundo). 
(38) «Si la decisión de los dirigentes nacionalistas consiste en alinearse con la democracia y el sistema constitucional y estatutario, dispondrán de la colaboración y ayuda de todos los estamentos sociales y políticos; si, por el contrario, su apuesta es por la esquizofrenia de una ambigüedad patológica, habrán de ser ellos y sólo ellos los que se enfrenten al terrorismo etarra que acabará por fagocitarlos» (ABC).

Los artículos de opinión que se suceden tras un nuevo atentado, ponen en marcha el mismo modelo:

(39) «A un lado, esa enfermedad mortal que llamaremos fascismo a falta de otro término más preciso; al otro, una sociedad asediada» (El País, 8-5-2000).

Estos son los principales modelos empleados para la noticia. Los ejemplos demuestran que no actúan aisladamente y que incluso varios de ellos pueden estar implicados en un mismo fragmento discursivo. Si se observan con detenimiento se obtienen los argumentos en torno a los cuales giran todos los comentarios: en el comunicado de ETA se sostiene que, a pesar de que se estaban dando pasos hacia la libertad de Euskal Herria, gracias a que el proceso habia madurado y a la apuesta que hizo ETA, el proceso se está pudriendo. Para los demócratas, ETA, al romper la tregua, ha roto el camino de paz. Los que apostaban por la paz han perdido y ETA, que ha vuelto a abrir su negocio, es una úlcera difícil de erradicar.

\section{La comprensión cognitiva del lenguaje metafórico}

La mayor parte de las metáforas y, en general, del lenguaje no literal, suponen una violación de la primera máxima de cualidad de Grice, pues se expresa algo falso. No obstante, los seres humanos somos capaces de desarrollar estrategias para comprender la supuesta falsedad de estas estructuras y lograr así una comunicación fluida. Esta circunstancia no es la excepción a la regla, ya que las lenguas naturales están plagadas de expresiones no literales que habrán de interpretarse.

En csta sección intentaremos esbozar, por un lado, qué procedimientos cognitivos permiten construir el lenguaje no literal, con especial atención a las metáloras y, por otro, qué mecanismos contribuyen a comprenderlas.

Desde una concepción más tradicional de la metáfora, Levinson (1989) considera que se deben a una capacidad psicológica general y crucial que afecta a muchos dominios de la vida humana: la aptitud para pensar analógicamente. Esa capacidad nos permite señalar las similitudes entre objetos o entre objetos y conceptos y llegar a una comprensión más cabal de estos. Ello supone que la analogía conduce a una identificación de fenómenos o circunstancias entre los que se observan ciertas coincidencias. 
No obstante, la capacidad metafórica no actúa aisladamente sino que se halla intcgrada en la posibilidad de suspender las relaciones entre referencia y verdad. Hacia los cuatro años, los niños normales la tienen muy desarrollada (Rivière, 1999) y hacia los siete años ya pueden comprender, e incluso usar bajo cicrtas condiciones, cl lenguaje metafórico (Levorato y Cacciari, 1992). La capacidad de suspender las relaciones entre referencia y verdad solo se lleva a cabo cuando el niño ha adquirido el núcleo estructural del lenguaje y cuando ha superado las diversas lases de metarrepresentación. Como afirma Rivière (1999), esta capacidad cmpieza a implantarse hacia los cuatro años y medio de edad, tras haber cvolucionado desde un primer nivel de pre-acciones o gestos metonímicos de comunicación (9-10 meses), pasando por un segundo nivel de suspensión de acciones instrumentales que requiere un cierto nivel de eficiencia y que ya se ciestaca como comportamiento plenamente humano (soplar para apagar el mechero, 12-18 meses) y un tercer nivel de suspensión de la realidad, que supone la creación de fieción (entre los 18 meses y los 4 años se desarrolla el juego de fícción). Finalmente, en el cuarto nivel se suspenden las representaciones simbólicas con el signilicado primero de las palabras y se crean metáforas. Estos procesos, habituales en los niños normales, se ven alterados en los niños autistas, que tienen serios problemas para interpretar el lenguaje no literal.

En suma, disponemos de instrumentos cognitivos para establecer analogías y para suspender las relaciones entre referencia y verdad. Sobre estas bases psicológicas se construye el lenguaje no literal y, en concreto, las metáforas.

Partiendo de la hipótesis de nuestra disposición cognitiva para generar metáforas, se propondrán algunas explicaciones pragmáticas sobre su comprensión. Estc hecho ha constituido el caballo de batalla de los teóricos de la metáfora; desde las teorías semánticas, como la de la interacción de rasgos o la de la comparación, a las tcorías pragmáticas de Grice, Searle o la teoría de la relevancia ${ }^{+}$, desde los modelos psicológicos del procesamiento derivado, que tienen muy en cuenta el significado literal, a los modelos constructivistas, que suponen capacidades cognitivas de procesamiento de los sentidos literal y figurado 5 .

El hecho que destacan las teorías pragmáticas actuales es que cl nucvo significado no se explica a partir de su semántica ni suponiendo la existencia de una comparación subyacente, sino que se ha de recurrir a diversos principios deciuctivos. Estas tcorías consideran como fundamental la tarea de la inferencia, pucs permite lograr los sentidos correctos que el hablante quería hacer manifiestos, pero que tal vez no se encontraban de forma explícita en el enunciado.

\footnotetext{
${ }^{4}$ Estas propuestals se encuentran reseñadas en Escandell (1996:cap. 11) o en trabajos particulares sobre la motálora como los de Marlínez-Dueñas (1993) o Chamizo (1997).

5 Belinchón (1999:348-358) resume cstas dos tendencias dentro de los estudios psicológicos sobre el lenguaje melafórico y recoge algunos de los experimentos realizados y las conclusiones obtenidas.
} 
Como se decía más arriba, el empleo de metáforas y de expresiones no literales transgrede una de las submáximas de manera, pues se afirma algo que no es verdadero. La relación que se establece entre el dominio origen y el dominio destino lleva a una conclusión falsa, si se parte de su literalidad. Por ello, hay que poner en marcha otros mecanismos interpretativos.

La tcoría de la relevancia redefine los conceptos de explicatura e implicatura enunciados por Grice y determina las diversas relaciones que se pueden inferir de una expresión. Sperber y Wilson (1994a) señalan que la metáfora, la ironía u otros tropos como la hipérbole y la metonimia no requieren de capacidades o procedimientos interpretativos especiales, pues son el resultado natural de algunas capacidades de carácter totalmente general que se emplean en la comunicación ${ }^{6}$. Por ello, también en estos casos la relevancia está garantizada. Cuando se emplea una metáfora lexicalizada se acotan un conjunto de implicaturas claramente determinadas por el conocimiento enciclopédico al que esta remite ${ }^{7}$. Si se dice que la ruptura de la tregua pone los pelos de punta a las víctimas del terrorismo se ponen de manifiesto unas premisas fuertemente implicadas que se han fijado junto a la locución. El receptor infiere que existe una relación entre el hecho físico de erizarse el vello y los sentimientos de exasperación y desesperación que pretenden transmitirse. Esta tarea inferencial se lleva a cabo acudiendo a las premisas implicadas por la locución, pues el sentido metafórico de la misma se consolidó en la lengua a la vez que las restricciones referidas a la fijación que presenta. Ello se demuestra en que, aun en el caso de que la expresión fuera inmotivada y, en consecuencia, se hubieran perdido los lazos con su origen, los hablantes nativos de español serían capaces de inferir estas implicaturas acudiendo a su conocimiento cnciclopédico y sin tener en cuenta, en ningún caso, la proyección metafórica que la sustenta. Para lograr los efectos cognitivos perseguidos por el hablante, el oyente habrá de relacionar esas premisas implicadas con el contexto, de forma que pueda obtener las conclusiones implicadas que de esta se derivan. La relevancia, por tanto, cstá garantizada cuando se hace manifiesto un supuesto a través de una unidad frascológica.

Cuando sc acude a una metáfora semilexicalizada o creativa las premisas que sc han de inferir no están tan establecidas, por lo que se ponen en marcha una amplia

\footnotetext{
"Otros trabajos relevantistas que han abordado los problemas de la metáfora son, a modo de ejemplo, los de Wilson y Sperber (1988) o el de Sun Song (1998). En el primero de ellos, los autores consideran que la supuesta interpretación de expresiones metafóricas no es tal, pues si la interpretación literal no funciona se habrá de buscar otra acomodada al contexto. En una línea similar a Sperber y Wilson, Sun Song (1998) rechaza la interprctación griceana de la metáfora y la metonimia a partir de su lectura literal y le concede un importante papel al oyente, que debe indagar sus efectos contextuales, así como el sentido en que se debe procesar.
}

${ }^{7}$ En esta misma idea incide Moeschler (1992). 
gama de implicaturas muy débiles. El escritor ha querido poner de manifiesto que, si bien cxisten unas premisas más fuertemente implicadas en ese enunciado y de ellas se extraen unas conclusiones aplicables al mismo, ello no excluye la inferencia de otras implicaturas más débiles. Cuando se emplea el modelo de LA PAZ ES UN CAMINO se recurre a un molde consolidado que facilita el procesamiento del mensaje. En estc caso, la adición de nuevas proyecciones metafóricas a partir de la metáfora básica permite ampliar el entorno cognitivo del receptor. Ello significa que las expresiones metafóricas sucesivas aportarán nuevos supuestos que confirmarán o modificarán el entorno contextual y que tendrán un efecto cognitivo determinado. La interpretación de las mismas se halla sujeto a los supuestos previamente manifestados por el escritor.

Cuando se usan otros modelos menos consolidados, como LA LUCHA ARMADA ES UN NEGOClO EMPRESARIAL, se ha de construir un entorno cognitivo que irá modilicándose o ampliándose con cada nueva información. Esto es, a partir de la primera expresión metafórica se irá aportando nueva información para lograr nuevos clectos cognitivos. Este hecho es especialmente palpable si el texto se apoya en este modclo, como ocurre con Fantasmas, artículo de Federico Jiménez Losantos, publicado en El Mundo, en el que se compara la situación del País Vasco con la del principal partido de la oposición, el PSOE. Tomemos un extracto de este:

(36) «Lo que convicrte en trágica y sombría una historia de fantasmas es el dinero; que un relato de muertos se encarne en la industria del cadáver. Los etarras, que no saben qué hacer con sus pistolas y con las vidas de quienes les votan, deciden abrir de nuevo el negocio para ganar tiempo, destrozar vidas ajenas para hacer como que hacen política micntras se desenreda la herencia hipotecada de Sabin Etxea, la finca del nacionalismo vasco. En el felipismo, del que ya se ve que el PSOE es sólo una piczil, menos importante que la mediática y la judicial, se vive también una historia de fanlasmas, de muertos mal enterrados, y de vivos que huyen de su sombra. Todo en la vida, la vida misma, puede entenderse como una dilación de la muerte pero no es posible una fantasía de eternidad que no incluya la paz de los cementarios y un cierto proyecto vital. Sucede que las funerarias son negocio. $Y$ que dos firmas comerciales en quiebra política se resisten a cerrar. Fantasmas on oferta. Navidad espectral».

(Federico Jiménez Losantos, El Mundo)

En este fragmento, las proyecciones metafóricas que aportan nueva información se construycn sintácticamente como nominales (la razón de la ruptura es el dinero, las funerarias son un negocio) y en torno a ellas giran otras de carácter predicativo (encarnarse en la industria del cadáver, abrir de nuevo el negocio, ganar tiempo) u oracional (dos firmas comerciales en quiebra politica se resisten a cerrar). La presentación de un cnunciado nominal facilita el procesamiento, pues este establece unas premisas que habrán de verse corroboradas o desmentidas en lo sucesivo. 
Estos enunciados iniciales sirven de guía para procesar las expresiones metafóricas sucesivas. Una gran parte de ellas se debe al mismo modelo cognitivo idealizado, hecho que facilita la inferencia de las implicaturas que el escritor ha querido manilestar.

\section{Conclusiones}

En el presente trabajo se han bosquejado algunas posibles vías para el estudio de las metáforas. El empleo de un corpus muy específico, referente a una única noticia, facilita la extracción de los modelos cognitivos idealizados en ella implicados. Los textos sobre la ruptura de la tregua por parte de ETA utilizan aquellos que permiten aprehender la realidad empleando hechos conocidos $y$ trasmiten una visión concreta del mundo: la paz es un camino, la lucha armada es un juego de cartas, la lucha armada es un negocio emperesarial o el terrorismo en es una enfermedad. Aplicados a este contexto concreto, se infiere que había una esperanza de acabar con el terrorismo en España tras la lïma de la tregua, pero la ruptura ha supuesto la quiebra de ese camino de esperanza. Desde esta perspectiva, cl terrorismo se analiza como una partida de cartas, un negocio empresarial o una enfermedad. Estos modelos cognitivos y, en especial las metáforas que se sustentan en ellos, constituyen recursos cognitivos que los seres humanos desarrollan de igual modo que otros mecanismos psicolingüísticos. La comprensión de los mismos está sujeta al contexto, pero también a lo que se infiere de estas metáforas, esto es, a las premisas implicadas que van directamente ligadas a las metáforas más lexicalizadas y a la gamá de implicaturas más débiles que se hallan conectadas a las libres o creativas.

\section{Referencias bibliográficas:}

Barcclona, A. (1998), «El poder de la metonimia». En Cifuentes, J. L. (ed.), Estudios de lingiiística cognitiva. Alicante, Universidad, págs. 365-380.

Belinchón, M. (1999), «Lenguaje no literal y aspectos pragmáticos de la comprensión». En De Vega, M.; F. Cuetos (Coord.): Psicolingüística del español, Madrid, Taurus, págs. 307-373.

Bickerton, D. (1969): «Prolegomena to a linguistic theory of metaphor», Foundations of Language, 5, págs. 34-52.

Carston, R.; S. Uchida (1998): Relevance Theory (Aplications and Implications), Amsterdam/Philadelphia, John Benjamins Publishing Company. 
Chamizo, P. J. (1998): Metáfora y conocimiento, Málaga, Universidad. Anejo XVI de Analecta Malacitana.

Cuenca, $\mathrm{M}^{\mathrm{a}}$ J.; J. Hillerty, (1999): Introducción a la linguïstica cognitiva, Barcclona, Ariel.

Escandell, Ma V. (1993): Introducción a la pragmática, Madrid, Anthropós.

Fauconnier, G. (1984): Espaces mentaux (Aspects de la construction du sense dans les langues naturelles), Paris, Minuit.

Fauconnier, G. (1991): «Subdivision cognitive», En Vandeloise, C. (Dir.), Sémantique cognitive, Communications, 53, págs. 229-248.

Fillmorc, Ch. J. (1985): «Frames and the semantics of understanding», Quaderni di Semántica, 6.2, págs. 222-254.

Fillmore, Ch.; P. Kay; M. O'Connor (1988). «Regularity and Idiomaticity in Grammatical Constructions: The Case of let alone», Language, 64, 3, pp. 501538.

Hamamoto, h., (1998): «Irony form a cognitive perspective». En Carston, R.; S. Uchida (1998), págs. 257-270.

Hilferty, J. (1995), «Metonímia i metàfora des d'una perspectiva cognitiva», Caplletra, 18, págs. 31-44.

Hopper, P. J. (1991): «On some principles of grammaticization». En Traugott, E.; B. Heine, (eds.) (1991), págs. 17-35.

Jaycz, J. (1994), «Pertinence lexicale et métaphore. Le cas du choix synonimique». En Moeschler, J.; A. Reboul, J-M. Luscher y J. Jayez (Éd.): Langage et pertinence, Nancy, Presses Universitaires.

Johnson, M. (1992): El cuerpo en la mente, Madrid, Debate.

Kleiber, G. (1990). La sémantique du prototype (catégories et sens lexical). Paris, PUF.

Lakoff, G. (1987). Women, Fire and Dangerous Things. (What Categories Reveal about the Mind), Chicago and London, The University of Chicago Press.

Lakofl, G.; M. Johnson, (1991): Metáforas de la vida cotidiana, Madrid, Cátedra.

Langacker, R. (1987), Foundations of Cognitive Grammar, I: Theoretical Prerequisites, Standford, Standord University Press.

Langacker, R. (1991), Foundations of Cognitive Grammar, II: Descriptive Application, Standford, Stanford University Press.

Lcvinson, A. C. (1989): Pragmática, Barcelona, Teide.

Levinson, A. C. (1995): «Three levels of meaning». En Palmer, F. R. (ed.): Grammar and Meaning. (Essays in honour of Sir John Lyons), Cambridge, University Press, págs. 90-115.

Levorato, M. Ch.; C. Cacciari (1992), «Children's comprehension and production of idioms: the role of context and familiarity», Journal of Child Language, 19 , págs. 415-433. 
Lichtenberk, F. (1991): «On the gradualness of grammaticalization». En Traugott, E.; B. Heine, (eds.) (1991), págs. 37-80.

Martínez-Dueñas, J. L. (1993): La metáfora, Barcelona, Octaedro.

Mescguer, LI. B. (Ed.): Metáfora i creativitat, Castellón Universitat Jaume I

Moeschler, J. (1989): Modélisation du dialogue. Représentation de l'inférence argumentative, Paris, Hermès.

Moeschler, J. (1992): «Métaphores et idiomes: compositionnalité, interprétabilité et inférence". En Tyvaert, J-E. (éd.): Lexique et inférence(s). (VIlème Colloque International de Linguistique, 14-16 novembre 1991), Paris, Klincksieck, págs. 97-114.

Moreno Cabrera, J. C. (1998): «On the relationships between grammaticalization and lexicalization». En Giacalone Ramat, A.; P. Hopper (eds): The Limits of Grammaticalization. Amsterdam, John Benjamins.

Portolés, J. (1993): «La metáfora y la lingüística: los atributos metafóricos con un enfático». En Demonte, V. (ed.): Gramática del español, México, Colegio de México, págs. 531-556.

Rivière, Á. (1999), «Bases ontogenéticas y cerebrales de la comprensión de metáforas: fundamentos en el desarrollo normal y alteraciones en los trastornos del desarrollo», Actas del V Simposio de Logopedia: Ciencia y Técnica. (Noviembre 1999), págs. 43-53.

Ruiz Gurillo, L. (1997): Aspectos de fraseología teórica española, Valencia, Universitat. Anejo XXIV de Cuadernos de Filología.

Ruiz Gurillo, L. (1998): La fraseología del español coloquial, Barcelona, Ariel. Ruiz Gurillo, L. (e.p.): Las locuciones en español actual, Madrid, Arco/Libros.

Salvador, V. (1994): «Noves perspectives sobre la metàfora». En Meseguer, Ll. B. (ed.), págs. 25-33.

Sperber, D.; D. Wilson, (1994a): La Relevancia. Comunicación y procesos cognitivos, Madrid, Visor.

Sperber, D.; D. Wilson, (1994b): «Postface (a la segunda edición de Relevance)», Oxford, Blackwell, págs. 255-279.

Sun Song, n. (1998): «Metaphor and metonomy». En Carston, R.; S. Uchida (1998), págs. 87-104.

Sweetser, E. E. (1990): From Etymology to Pragmatics: Metaphorical and Cultural Aspects of Semantic Structure, Cambridge, Cambridge University Press.

Sweetser, E.; G. Fauconnier (1996), «Cognitive Links and Domains: Basic Aspects of Mental Space Theory». En Sweetser, E.; G. Fauconnier (eds.), Spaces, Worlds and Grammar, Chicago and London, The University of Chicago Press, págs. 1-28.

Traugott, E. (1989), «On the rise of epistemic meanings in English: an example of subjectification in semantic change», Language, 65, págs. 31-55. 
Traugott, E. (1997), «Semantic change: an overview», Glot, 92/10, diciembre 1996, 3-7.

Traugott, E. (c.p.1): «The rhetoric of counter-expectation in semantic change: A study in subjectification».

Traugott, E. (c.p.2): «The role of the development of discourse markers in a theory of grammaticalization». Bentley, D.; J. C. Smith (eds.). Proceedings of the XII International Conference of Historical Linguistics. Amsterdam, John Benjamins. (Agosto de 1995).

Traugott, E.; B. Heine, (eds.) (1991): Approaches to Grammaticalization, Amsterdam, Benjamins.

Ungerer, F.; H.-J. Schmid (1996): An Introduction to Cognitive Linguistics, London, Longman.

Vega, M. (1998), «La actividad metafórica: entre razón calculante y razón intuitivà, Espéculo, 10, (revista electrónica),2/5, págs. 1-7.

Villanueva, $M^{a}$ L. (1994), «Metáfora y discurso periodístico. Análisis contrastivo de crónicas y reportajes en periódicos franceses y españoles». En Meseguer, Ll. B. (cd.), págs. 277-298.

Wilson, D.; D. Sperber (1988), «Representation and Relevance». En Kempson, R. M. (De). Mental representations: The interface between language and reality, Cambridge, Cambridge University Press, págs. 133-153.

Wilson, D.; D. Sperber, (1993): «Linguistic form and relevance», Lingua, 90, págs. 1-25.

Yus, F. (1995-1996): «La Teoría de la Relevancia y la estrategia humorística de la incongruencia-resolución», Pragmalingiiística, 3-4, págs. 497-508. 